\title{
RELATIONSHIP BETWEEN CONTINUOUS IMPROVEMENT PRACTICES AND PROJECT MANAGEMENT APPROACH
}

\author{
Aneta Kucińska-Landwójtowicz ${ }^{1}$
}

\begin{abstract}
Continuous Improvement is a concept recognized in literature and management practice as essential in today's business environment. This article deals with the analysis of the importance and placement of project management in the implementation and application of Continuous Improvement (CI) practices in manufacturing companies. The first part of the article presents the conclusions resulting from the literature review of the improvement projects management. The problems appearing in this area of the organization's activity were analyzed. Then are presented the results of the empirical research carried out in the production company. A case study has allowed the characteristics of the realized projects to be determined and the identification of the factors that are conducive to and obstructive to the achievements of their objectives.
\end{abstract}

UDC Classification: 658.6; DOI: http://dx.doi.org/10.12955/cbup.v6.1168

Keywords: project management, Continuous Improvement, improvement projects.

\section{Introduction}

Currently, the concept of Continuous Improvement (CI) is treated as a way to maintain and improve the company's competitiveness by using all their employees' knowledge and involvement (MarinGarcia et al., 2008). Analysis of the concept definition of "continuous improvement" allows us to state that it is related to the construction of a permanent improvement culture (Bhuiyan \& Baghel, 2005), as well as also to launch a series of procedures letting the organization improve what it is currently doing (Bessant et al., 2001). A. Paul Brunet and S. New indicate, however, that CI make up ubiquitous and continuous activities, besides the standard roles of participants in order to identify and achieve results, which contribute to the achievement of organizational goals (Paul Brunet \& New, 2003). The next definition defines CI as improvement initiatives that increase success and reduce errors (Bhuiyan \& Baghel, 2005). The emerging terms "a series of procedures", "actions outside standard roles" or "initiatives" draw attention to CI's connection with the need to launch various undertaking types which would allow it to accomplish the assumptions of the discussed concept. Despite the fact that the definitions also emphasize that CI stands for small changes that do not require large investments, experience shows that a large amount of work and high organizational efficiency is necessary to launch a new way of thinking and the resulting practices. This need is undoubtedly stronger after the analyses of a set of specific values, principles and many techniques recognized as basic CI procedures. They require the introduction of solutions that in many cases constitute a new challenge for the organization, e.g. Total Productivity Maintenance, Single Minute Exchange of Die (SMED) or Just in Time. Their implementation is a sequence of unique, complex and related tasks linked by a common goal. The intention of the management should be the introduction of them within a specified period, without exceeding the set budget and, of course, according to the assumed requirements.

This basic characteristic makes one recognize that these are such projects, which are to be wisely initiated and defined, planned, organized and implemented before they become a permanent practice. Organizational errors at the implementation stage of these programs are particularly risky, mainly due to the simultaneous shaping of the organizational culture and work environment, which as a result may have both positive and negative effects on the environment. At this level, it is required to set up project and task teams which also include managers deriving from the organization's various levels. The most important task of each project is the accomplishment of the basic goal as well as specific objectives. The main goal must result from the adopted CI strategy, and all projects should be accomplished in a specific order.

Research has shown that a lack of understanding concerning organizational culture and a fragmented and inconsistent approach to the use of the concept's principles may lead to an unsuccessful implementation of it (Wirkus et al., 2014). Therefore, the company's management, willing to introduce CI, should apply a project approach, effective against new and complex initiatives, including organizational ones. The project management resulting from it, understood as a set of logically arranged activities related to planning, organizing, motivating and controlling, the application of

\footnotetext{
${ }^{1}$ Department of Production and Services Quality Engineering, Faculty of Production and Logistics Engineering, Opole University of Technology, a.kucinska@ po.opole.pl
} 
which is aimed at the achievement of the objectives, which have been set by the goal's initiator (AlSmadi, 2009), may become a perfect way to achieve it. The research conducted in Poland (Trocki, 2014) revealed that the major internal benefits resulting from the application of the project approach include: risk reduction (43.4\%), project implementation on time (36.1\%), improvement of project results $(34.9 \%)$ ), improvement in resources utilisation (28.9\%), stronger business / financial control $(26.5 \%)$, increase in operational efficiency $(26.5 \%)$, implementation of the project in accordance with budget $(21.7 \%)$ and the project implementation in accordance with range $(20.5 \%)$. It is therefore worth using this knowledge while implementing CI principles and techniques, in order to reduce to a minimal level the risk of failure while introducing this concept of management.

The aim of the article is to present the importance and place of project management in the implementation of the assumptions of continuous improvement in manufacturing enterprises. Based on the analysis of the literature, attention was paid to the principles that should be applied in the management of improvement projects and the errors appearing in this area of activity were discussed. Then, good practices applied in the analyzed production company were presented, affecting the efficiency in implementing the improvements.

\section{Research methodology}

The first part of the article uses literature analysis to identify good principles and errors appearing in the management of improvement projects. Additionally in order to achieve the purpose of the article, a case study was carried out, while applying the principle that its application is useful when the knowledge of the studied phenomenon is limited (Eisenhardt \& Graebner, 2007). It takes place in terms of the undertaken research issue, which has not been analysed yet in operating in Poland, large manufacturing companies. Therefore, the study was carried out in the mode of targeted selection in a large enterprise producing electronic devices. The company is pursuing its goals, developing subsequently in the field of application of improvement techniques and building an ever stronger organizational culture based on the principles of continuous improvement. This case was chosen because:

- the company's management has recognized the principles of continuous improvement as priorities in the company's strategy, which prepares the basis for assessment of the ability to use key CI practices,

- the company's management in a thoughtful and orderly way implements and applies all key practices included in the Continuous Improvement, which enables observation and evaluation of their adaptation processes,

- a structured system of activities related to CI was created in the company, which eliminates the randomness in the selection of CI practices,

- employees of the company demonstrate a high level of knowledge regarding the CI concept, which facilitates interviews conduction,

- there is documentation in the company confirming the use of the CI practices, what permits the use of documentation analysis,

the top management notices difficulties appearing in a pursuit of the continuous development of CI practices and expressed the need to assess the ability to improve and identify the strengths and weaknesses of the implemented practices.

\section{Management of improvement projects - good rules and errors}

Improvement actions being accomplished in enterprises which are operating in accordance with the CI concept may be divided into:

- Kaizen projects, focusing on the accomplishment of small, daily improvements, using intuition, knowledge, skills and experience gained at their workplace,

- improvement projects with a greater range and stage of completion, unique but conducted according to a previously fixed plan, with a particular start and end date, with a clearly defined goal.

Both types of projects are characterized by a high level of diversity, depending on the problem which is being solved, its scope and conditions. In many cases, they also require an analysis of the problem's surrounding and anticipation of what might be the effects of the changes being introduced elsewhere 
in the enterprise. Therefore, organizations should carry out systemic improvement, which would permit the implementation of improvements taking into account the whole system. While accomplishing the CI concept, it is also important that the launch of improvement projects does not have the character of sporadic initiatives. One should strive to build a system of undertakings oriented at permanent implementation of changes strengthening the position of the entire enterprise, while complying with the following principles:

- ensuring that all improvement projects are part of the organization's strategic goals,

- ensuring adequate material resources for the implementation of projects,

- providing the staff who are prepared to manage improvement projects,

- shaping the attitude of engagement among project contractors,

- promoting the results of completed projects.

Proper management of the improvement project means assignment of responsibilities and obligations, defining the project implementation schedule, risk analysis, completion of the plan according to the plan, monitoring progress and immediate reaction in case of disturbances. In the case of projects which are implemented in the CI environment, the techniques supporting their implementation are: the Deming cycle, the DMAIC (Define, Measure, Analyze, Improve, Control) cycle and the 8D methodology.

The results analysis of the research, that is carried out in enterprises which are applying the design approach in the improvement activity, indicates that most common errors are: poor selection (Gijo, 2011; Keim, 2011) and resources (Snee, 2010) of the project. Problems also appear when project selection is not aligned to the enterprise's strategy (Kornfeld \& Kara, 2013), and for example in a company aiming at quality, project goals focus on cost reduction. Another obstacle in effective project management is too large of a scope (Hariharan, 2006), selected using inappropriate methods (Kornfeld \& Kara, 2013) and the assessment concerning the number of implemented projects as a measure of success. This leads to sealing of incomplete projects or selecting ones that do not bring significant results but permit their efficient implementation.

In the area of project management, it is most frequently emphasized that a project will struggle if it is poorly defined, lasts more than six months, has infrequent team meetings or has little technical support from the project manager. Obstacles in an effective operation constitute also: the slow pace of the project team's work, interruptions in its operation, and poor selection and application of methods or tools (McLean et al., 2017). Attention is also drawn to errors resulting from incomprehension and lack of analysis of the connection between the implemented project and the surrounding.

Further obstacles are identified in the project's resources area. Keim points out to the selection of such people to the project teams, who do not have enough time for this job (Keim, 2011). Another issue is also the situation when the project teams are too large (Snee, 2010). Hariharan, on the other hand, draws attention to such issues as: lack of involvement presented by team members, leadership deficiencies in the project or key people's withdrawal due to the pressure deriving from current tasks (Hariharan, 2006). The effectiveness of the project team is also weakened due to the team members' rotation and shortage of access to necessary data.

\section{Good practices in managing CI projects on the example of an industrial company}

Along with the decision on the CI concept implementation, the management board prepared an action schedule that would enable this goal to be achieved. During this period of the strategy concerning the project development, the "top-down" approach was adopted. Projects were created due to the top management's initiative, and in the next steps their tasks constituted the basis for the development of partial projects at the organization's lower levels. It was initiated by the launch of the improvement program which began at the managerial and team level. It was the first formal project related to the new operation concept, and the company's management was its sponsor. Relating to the practices which were used there, it was characterized by a high level of novelty and belonged to a group of organizational projects of significant importance for the new strategy implementation. Its effect was related to the achievement of organizational goals, and what is important, it influenced the shaping of employees' attitudes. Therefore, it was important to minimize any problems occurrence and to ensure a high level of its quality. The project was implemented in accordance with four phases: concept, planning, implementation, and completion. It ended with a positive result. 
Subsequently, a program of improvement actions at the managerial and team level was launched, and accomplishments of projects in the area of production related to work standardization, $5 \mathrm{~S}$ technology was ignited as well as launching of the Kanban cards flow began, conducted by the so-called permanent teams of continuous improvement. Five such groups were put forward, which performed their next tasks with the application of the project approach. At the same time, projects aimed at improving employees' qualifications were carried out.

A year later, at the level of the company's management, another organizational project was initiated aimed at the launch of the operation of a new organizational unit, who would be responsible for the company's continuous improvement program. One of the new department employees' most important tasks was to organize and coordinate the implementation of improvement projects, which began to be launched in the enterprise on an even wider scale, and also by appointing new project teams, especially for the indicated problems. That is why among the requirements set for the future department's employees include: experience in the implementation of projects, the ability to work in a team, the ability to communicate, a broad view on the processes being implemented throughout the company, knowledge of methodologies supporting project management. The undertaking aimed at launching the operation of the new organizational unit, similarly to the previous one, was characterized by a high level of novelty and belonged to a group of organizational projects bestowed a significant importance for the enterprise. The project of launching the new department was successful and they very efficiently started to implement the tasks entrusted to them. Their scope includes:

- creation, implementation and enforcement of standards concerning improvement projects management being accomplished in the enterprise,

- preparation of reports regarding implemented projects,

- creating an archive that is a certain knowledge base about completed projects,

- monitoring the progress and timeliness of projects being implemented,

- monitoring the projects effectiveness in relation to the adopted indicators,

- reporting about the projects progress to the top management.

It can be noted that these tasks are similar to those assigned to project management offices working in a multi-project work environment (Spałek \& Bodych, 2012). Of course, they differ in size and scope of the conducted projects, but the idea of their operation seems to be similar.

Another project initiated by the top management was to launch a suggestion system covering all the company's employees, working in each organizational unit. Responsibility for its accomplishment rested with the head of the continuous improvement department, who became its leader. Similarly, as with the previous project, the launch of the suggestion system was characterized by a high level of novelty and belonged to organizational projects of significant importance for the enterprise.

The accomplishment of the three projects presented above was held during the first stage of the CI concept introduction in the company and it was associated with a very large involvement of the top management. Four phases were identified in their accomplishment: concept, planning, implementation and completion. They all had a specific goal, beginning and end dates, as well as budget. In case of all projects, the project's team and its leader were assigned. The projects importance was enormous both from the point of view of the operational objectives being pursued as well as regarding the new organizational culture in the company shaped during that period.

The second stage in the concept development is the continuation of the activities implementation in the teams' work areas regarding continuous improvement and suggestion system, as well as the introduction of a new approach to the process improvement based on methods related to the implementation of the Lean Manufacturing concept, including Total Productivity Maintenance, reduction of waste, organization of a suction production flow and value added analysis. It was connected with the launch of the implementation of many improvement projects, where the end of one was connected with the launch of another. At the same time, projects aimed at improving employees' qualifications were also continued. Improvement projects were characterized by diversity and uniqueness. In many cases, they were created interactively through consultations and arrangements between top management and operational level managers.

At the third stage of the concept development of the company's continuous improvement, new activities in the area of improvement appeared, namely launching Lean activities regarding 
administration and development too. Additionally, projects were launched in accordance with the DMAIC methodology. It is transparent and contains all stages resulting from the logic of dealing with solving problems or achieving set goals.

With a large number and variety of ongoing improvement projects, a certain standardization of activities has become indispensable. The idea of the CI concept is understood as a continuous improvement of processes, whereas knowledge about the projects which are implemented in a given process is the basis for conducting activities in line with the Deming cycle. That is why it is crucial to collect, analyse and share it so that it can be used for further improvements. The solutions adopted in the surveyed company allow to reduce the number of duplicated errors in the implemented projects. Each project is defined and planned. Opening meetings, formal attribution of resources to the particular project, determination of indicators which enable to monitor its effectiveness and results validation are a permanent practice. Project schedules are also prepared, which facilitates reporting the state of the project. One of the very good practices is to keep relevant documentation and to coordinate projects by the CI department. It has become, somehow, a project management office and a knowledge database regarding ongoing projects. It is also responsible for the flow of information on projects and the supervision and administration of the electronic database. Each project ends with a summary meeting at which conclusions from its implementation are being analysed regarding both the project purpose and the experience acquired during its course.

The project management standardization adopted in the company allows it to avoid waste in the form of duplication of the same activities related to the readying of appropriate rules, procedures and documents for the implementation of projects. This also applies to "learning" how to use them. Unification of the adopted action methods shortens the preparation for the project conduct, avoids organizational confusion regarding its formal launch and implementation, and reduces the need to prepare employees for work in a project team. The solutions used in the company concerning the gathering and transmission of information regarding implemented projects, about their status and work progress allow to share coherent data with interested parties (accounting department, supervisors of people involved in the project, other project managers, project sponsor, etc.). It is an important source of information about the project resources and their degree of use, which makes it easier to answer the question whether the project will fit within the planned budget, and whether its deadline will be met.

\section{Conclusion}

The analysis presented in the article draws attention to the pragmatic aspects of accomplishing the concept of continuous improvement in a production enterprise in relation to the management of a number of diverse projects aimed at introducing principles and techniques that make up the CI. It seems reasonable to say that such a company faces a challenge of managing a projects portfolio, that is made up by a group of projects or programs implemented in the organization that are aimed at strategic goals, which use the same resources and have to compete for funds (Nicholas \& Steyn, 2012). The research conducted in the company shows that the number of implemented projects are growing every year and an increasing number of employees are participating in it. These are small projects related to the process improvement throughout the whole enterprise, and the end of one coincides with the beginning of the next. Interviews conducted among senior and middle- stage managers allowed to identify several key factors conducive to achieve the objectives of CI projects:

- adopted standardization for initiating and accomplishing projects,

- coordination and organizational support of the CI department,

- precisely defined project goals,

- project goals consistent with the company's strategy,

- providing resources,

- appointing well-qualified and experienced project managers,

- appointing project teams and appropriate delegation of authorization,

- management support.

The factors that hinder the implementation of projects are as follows:

- a large number of implemented projects which translate into difficulties associated with decision making on: which projects are to be approved for implementation, which are to be postponed, and which are not be available at all, 
- difficulties in allocating human resources and employees' uneven workload in project teams,

- time limits.

Finally, it should be emphasized that the application of the project approach supports the implementation of the strategy adopted by the company and the resulting implementation and application of CI principles and techniques. In contrast, characteristics of projects which were carried out allow to direct their leaders onto the selection and application of project management methods and tools adequate to the category of small organizational projects.

The limitation of the research lies in the fact that the results of the study are based on a single case study; therefore, caution is required before making generalizations on the basis of the data. Further research is required to gather analyses results within a larger number of enterprises, which would enable to present more universal conclusions.

\section{References}

Al Smadi, S. (2009). Kaizen strategy and the drive for competitiveness: challenges and opportunities. Competitiveness Review: An International Business Journal, 19(3), 203-211.

Bessant, J., Caffyn, S., \& Gallagher, M. (2001). An evolutionary model of continuous improvement behaviour. Technovation, 21(2), 67-77.

Bhuiyan, N., \& Baghel, A. (2005). An overview of continuous improvement: from the past to the present. Management decision, 43(5), 761-771.

Eisenhardt, K. M., \& Graebner, M. E. (2007). Theory building from cases: Opportunities and challenges. Academy of management journal, 50(1), 25-32.

Gijo, E. V. (2011). Eleven ways to sink your Six Sigma project. ASQ Six sigma forum magazine, 11(1), 27-29.

Hariharan, A. (2006). CEO's guide to Six Sigma success. ASQ Six Sigma Forum Magazine, 5(3), 16-25.

Keim, E. M. (2011). Shortcuts don't get you there faster. ASQ Six Sigma Forum Magazine, 10(3), 31.

Kornfeld, B., \& Kara, S. (2013). Selection of Lean and Six Sigma projects in industry. International Journal of Lean Six Sigma, 4(1), 4-16.

Marin-Garcia, J. A., Pardo del Val, M., \& Bonavía Martín, T. (2008). Longitudinal study of the results of continuous improvement in an industrial company. Team Performance Management: An International Journal, 14(1/2), 56-69.

McLean, R. S., Antony, J., \& Dahlgaard, J. J. (2017). Failure of Continuous Improvement initiatives in manufacturing environments: a systematic review of the evidence. Total Quality Management

\& Business Excellence, 28(3-4), 219-237.

Nicholas, J.M., \& Steyn, H. (2012). Zarządzanie projektami. Wolters Kluwer SA.

Paul Brunet, A., \& New, S. (2003). Kaizen in Japan: an empirical study. International Journal of Operations \& Production Management, 23(12), 1426-1446.

Snee, R. D. (2010). Lean Six Sigma-getting better all the time. International Journal of Lean Six Sigma, 1(1), 9-29.

Spałek, S., \& Bodych, M. (2012). PMO: praktyka zarządzania projektami i portfelem projektów

w organizacji. Helion.

Trocki, M. (2014). Organizacja projektowa. PWE.

Wirkus, M., Roszkowski, H., Dostatni, E. \& Gierulski, W. (2014). Zarzadzanie projektem. PWE. 